\title{
Effectiveness of In-Service Elementary School Teacher Professional Development MOOC: An Experimental Research
}

\author{
Eirini Tzovla \\ Department of Molecular Biology \& Genetics, Democritus University of Thrace, Evros, Greece \\ ORCID: 0000-0003-2611-2783 \\ Katerina Kedraka \\ Department of Molecular Biology \& Genetics, Democritus University of Thrace, Evros, Greece
} ORCID: 0000-0002-8180-3643

Thanassis Karalis

Department of Educational Sciences \& Early Childhood Education, University of Patras, Achaia, Greece ORCID: 0000-0002-8564-8812

Marina Kougiourouki

Department of Primary Education, Democritus University of Thrace, Evros, Greece

ORCID: 0000-0003-3398-2912

Konstantinos Lavidas

Department of Educational Sciences \& Early Childhood Education, University of Patras, Achaia, Greece ORCID: 0000-0003-2225-1137

Received: 19 May 2021

Accepted: 30 Jul 2021

\begin{abstract}
Teachers' Professional Development Massive Open Online Courses (TPD-MOOCs) are a new form of MOOCs and have influenced an intense research interest. This study reports on the design and implementation of a TPD-MOOC which utilizes digital educational content and Open Educational Recourses (OER) and supports in-service elementary school teachers to enhance their self-efficacy beliefs. In the design framework we take into consideration the findings of previous research and the educational needs of the participants. We conducted an experimental design research and compared the teachers' self-efficacy beliefs before and after their participation in a TPD-MOOC. A total of 251 teachers enrolled in this course and 142 of them completed it. We used quantitative data to measure the enhancement of teachers' self-efficacy beliefs and the effectiveness of the course. The results provide evidence that our TPD-MOOC improved in service elementary school teachers' self-efficacy beliefs in teaching biological concepts. Recommendations are made for future research.
\end{abstract}

Keywords: teacher professional development, MOOC, self-efficacy beliefs, elementary education, improving classroom teaching

\section{INTRODUCTION}

Constant scientific, social and technological changes affected, among other fields, education, making knowledge acquired by in-service teachers during their university education insufficient. Hence a new role of 
teacher emerges, that of the lifelong learner who is called upon to be developed professionally to keep up with changes and therefore, being able to participate in redesigned learning environments (Kedraka, 2008).

During the last decades there has been an intense discussion about the forms of teachers' professional development (Aji \& Khan, 2019). The evolution of online learning environments could support professional development programs and reform education. In this regard some start-ups such as Coursera and Udacity in USA, a great number of initiatives in European level such as FutureLearn, European Schoolnet Academy and some others in international level such as XuetangX gave opportunities to those interested to participate in flexible courses for free, which are known as MOOCs (Massive Open Online Course). MOOCs are online open courses (Kaplan \& Haenlein, 2016) to anyone interested, a plethora of them were offered by universities and recently many providers offered paid courses. MOOCs can be grouped into $\mathrm{CMOOCs}$ and $\mathrm{xMOOCs}$ which differ in the pedagogical approach and methods they use (Depover et al., 2017). cMOOCs are based on the idea that learning happens within a network, where learners create and construct knowledge (Siemens, 2013). xMOOCs approach learning more as an individual process and are more teacher-led, have specific structure and assignment (Ross et al., 2014). Apart from these, new forms have emerged, combining features of cMOOCs and XMOOCs and offering several choices in different areas (Bruff et al., 2013).

As for the last decades' professional development projects, MOOCs have been offered especially for teachers (Teacher Professional Development, TPD-MOOCs) and have influenced an intense research interest (Ostashewski, 2018). The teachers' professional development has been the concern of many researchers (Rozimela, 2020; Swart et al., 2019), who proposed a variety of forms, including MOOCs, to promote it (Firmin et al., 2014; Koukis \& Jimoyiannis, 2017, 2019) but the effectiveness of TPD-MOOCs- that is the improvement of teacher's self-efficacy beliefs- is still an underestimated field (Wang \& Zhu, 2019; Zhu et al., 2020).

The present research proposes a TPD-MOOC for improving elementary school teachers' self-efficacy beliefs and at the same time investigates its effectiveness through an experimental research. This study is of great importance as technological evolution and the COVID-19 pandemic (Tzovla \& Kedraka, 2020) have mandated the implementation of most professional development courses through remote teaching and distance education. MOOCs could be considered as a modern professional development's tool, continually gaining intense educational and pedagogical interest and research, with Fishman et al. (2013) arguing that there are no significant differences in learning outcomes whether teachers attend programs with physical participation or online.

\section{LITERATURE REVIEW}

Various researchers have defined teachers' professional development (TPD) as a concept synonymous to the transformation of education (Sykes, 1996) and attribute to it the change in thinking, behavior, and attitudes of in-service teachers (Evans, 2014). Kedraka (2008) notes that professional development includes personal development, career development, teaching competence and scientific training and Bolam (2000) defines professional development as the enhancement of professional knowledge and skills, which all contribute to effective teaching.

However, effective teaching is directly related to the teacher's self-efficacy beliefs, which Bandura (1997) defines as the belief in the individual's capacity to organize and execute actions required to produce achievements. Bandura (1997) analyzes them in personal self-efficacy beliefs and outcome expectancy beliefs and notes that these affect the educational practices that are chosen by teachers, the learning outcomes, and the self-efficacy beliefs of students. As consequence the teachers' professional development courses worldwide are geared in this direction (Schroeder, 2019).

In recent years, several TPDs-MOOCs have been implemented. They mainly investigate the enhancing teachers' professional development through issues of improvement, such as content knowledge, beliefs, and teaching practices of in-service and pre-service teachers, take place in different countries and use quantitative and qualitative approaches (Gordillo et al., 2019; Menon \& Banerjee, 2019; Rahimi et al., 2018). Nevertheless, only a narrow range of studies have focused on the effectiveness of TPD-MOOCs (Gamage et 
al., 2016; Reddy \& Pabolu, 2019) and very limited studies investigate the MOOCs impact on teachers' selfefficacy beliefs (Aji \& Khan, 2019; Gosselin et al., 2010; Mertasari \& Candiasa, 2020; Wang \& Zhu, 2019; Yoo, 2016).

Specifically, Aji and Khan (2019) measured the self-efficacy beliefs of 16 math's and 18 science teachers in the USA, who participated in a workshop related with teaching math's and physics concepts to middle school students. They used STEBI-A and MTEBI instrument (pre- and post-survey) and they found improvement of teachers' self-efficacy. Gosselin et al. (2010) explored the content knowledge, science teaching efficacy beliefs and sense of community of 51 elementary school teachers in the USA through qualitative and quantitative data who participated in an online Laboratory Earth course. They advocated that the participants improved and maintained their content knowledge and science teaching efficacy beliefs and they were satisfied with their belonging to an online community. Similarly, Mertasari and Candiasa (2020) investigated through a questionnaire the self-efficacy of 58 pre-service mathematics teachers in Indonesia who participated in an online learning community. They indicated that the participants improved their selfefficacy. Wang and Zhu (2019) measured the effectiveness of a MOOC-based flipped learning at the beginning and end of the study, through a questionnaire and interviews. They indicated no changes in self-efficacy of undergraduate chemistry students in China but improvement in their knowledge and their learning performance. Finally, Yoo (2016) investigated through quantitative and qualitative data the impact of an online professional development course on 148 teachers' and school educators' self-efficacy in the USA and reported that they increased their self-efficacy.

\section{RESEARCH OBJECTIVES}

Given the increased interest about TPD-MOOCs, we developed and implemented a course aiming at contributing to the underestimated field of effectiveness of TPD-MOOCs. The present research proposes a TPD-MOOC and at the same time investigates its effectiveness in the field of self-efficacy beliefs through an experimental research. Specifically, we explore whether there is an improvement in teachers' self-efficacy beliefs after the attendance of a TPD-MOOC, which used digital educational content and OER as well as creating a productive learning environment, which focus on networking, supported learning and sharing digital educational content and OER in an active online learning community.

Subsequently, we present the design framework of the course, describe its structure, investigate its effectiveness in two groups of in-service elementary school teachers, discuss the results of the study and finally make suggestions for further investigation.

\section{DESIGNING THE TPD-MOOC}

Our TPD-MOOC focused on boosting teachers' self-efficacy beliefs by shaping an active online learning community, providing them with digital educational content aligned to the curriculum and in accordance with their educational needs, asking them to implement what they learnt in the course in the classroom and evaluate the learning outcomes. The instructional design model we relied on to develop our course was the hybrid design scheme of TPD-MOOCs initially proposed by Koukis and Jimoyiannis $(2017,2019)$. It was considered the most appropriate for the causes of our study because it meets the educational profile of Greek teachers. Following the above scheme, the course had a specific structure, content and evaluation and was based on teachers' active participation through the elaboration of assignments, and peer-supported learning. Koukis and Jimoyiannis introduced and implemented for the first time the above scheme, addressing it to Greek language teachers who taught in secondary education. We maintained the basic concept of their scheme and customized it so that it could be applied to Greek in-service elementary school teachers, who teach the biological concepts. In this term, we enhanced effective online learning through enabling dialog and creativity, fostering collaboration, encouraging reflection, applying theory to practice, and motivating the participants in an online community of peers (Conole, 2014). The course was communitycentered, and we structured it to strengthen individual engagement (Onah et al., 2014) and networking 
(Ostashewski, 2018). In addition, we put emphasis on relations among participants, educators, and digital educational resources (Goodyear et al., 2006).

Moreover, we enhanced self-regulated learning, because the existing research findings indicate that teachers prefer not only to enroll in structured MOOCs (xMOOCs mode) but also, they prefer self-directed learning paths and collaboration within learning communities (cMOOCs mode) (Karlsson et al., 2014; Koukis \& Jimoyiannis, 2017). In this term the course was based on flexibility. The participants had the choice to adjust their participation to their workplace schedule, adapt it to meet their individual learning needs and communicate with their colleague teachers when they have time. Specifically, it was asynchronous, facilitated participants to take control of their learning and enhanced opportunities to learn at their pace (Moreno-Marcos et al., 2020), reflecting the basic idea of learning that MOOCs brought in.

Furthermore, we tried to reinforce active learning (Reddy \& Pabolu, 2019) enabling the participants to act as "learners" and "designers". The aim of the final task was to create educational activities applicable in the classrooms both by themselves as well as by other members of the online learning community. Ultimately, they contributed with their knowledge and experiences to the collective experience of the online learning community.

Additionally, we put emphasis on the role of the educators as critical friends who constructs the active learning environment (Dimitriadou et al., 2021; Karalis \& Koutsonikos, 2003; Pavlis-Korres et al., 2009; Reddy \& Pabolu, 2019). Therefore, we have weakened their role as guiders by attributing this role to the members of the online learning community and strengthened their role as encouragers who support teachers to reach knowledge on their own.

In the light of the previous studies arguing that low effectiveness of a MOOCs course can lead to dropout (Gamage et al., 2016), we put emphasis on the needs of the participants (Oh et al., 2019). In this regard, we initially investigated their educational needs through an appropriate research instrument, configured the course and the educational material according to the pedagogical principles and the methodology of adult education and distance education learning (Aldowah et al., 2019); selected an easy to use and familiar to participants platform (Khalil \& Ebner, 2014); provided well organized sections (Goh et al., 2018); created a support forum (Greene et al., 2015); uploaded instructions to avoid overloading forums (Moreno-Marcos et al., 2020); created reflection activities (Goh et al., 2018); automated assessments quizzes and sent timely the passwords and issued a certificate of attendance (Goh et al., 2018).

Finally, to investigate the MOOC's contribution to improving teachers' self-efficacy beliefs the participants filled the questionnaire bio-STEBI-A, which measured both teachers' personal self-efficacy beliefs, that is their capability for success in teaching biological concepts and their outcome expectancy beliefs, that is the levels of confidence teachers have that their students will learn the biological concepts, at the last week of the course. At the same time the participants completed an online questionnaire regarding their satisfaction of the course (Tzovla et al., 2021). This questionnaire used both 15 (out of 95) statements of the instrument of Koukis and Jimoyiannis (2019) and the Critical Incident Questionnaire (CIQ) of Brookfield (Keefer, 2009). The instrument description partly reproduces their wording.

\section{COURSE UNITS BY WEEK}

The TPD-MOOC lasted from September $28^{\text {th }}$ to November $1^{\text {st }}, 2020$, was entitled "Teaching biological concepts in Primary Education using Digital Educational Content and Open Educational Resources". It aimed to support Greek in-service elementary school teachers' self-efficacy beliefs through utilizing digital recourses in teaching biological concepts. After the invitation for the course in May 2020, 349 teachers, who had expressed interest in it, were informed to enroll. There is a small rate of drop out. 251 registered to attend the course and 142 successfully completed it (56.57\%).

In Greece the most common platforms used for distance education learning for teachers' professional development are Moodle and Open eClass. We decided to use the Open eClass platform for our course because it is easy and simple to use but mainly because it was familiar to most in service elementary school 
teachers in Greece, since they used it during the emergency remote teaching, which took place during the COVID-19 pandemic. The course lasted 5 weeks and the units were structured on a weekly basis. Each unit included independent short pdf files, videos, best practices of using digital educational content and OER in classroom, self-assessment tests, educational web links, additional educational material, and a forum for the topic of the week so as to enable participants to share ideas to integrate digital educational content in pedagogical approach in their classrooms. Moreover, we used an inquiry approach, and asked participants to search and suggest digital educational content and OER appropriate for teaching the biological concepts in Primary School. The passwords of the course were sent to the teachers on September $18^{\text {th }} 2020$, so to get acquainted with the platform.

From the beginning of the TPD-MOOC, the participants were encouraged to actively participate in an online learning community and submit their reflections, experience and views. Specifically, they posted comments in the forums of each course unit, offered ongoing support to their peers, and a lot of questions, which when raised were answered by other participants. Moreover, they designed and implemented activities based on digital educational recourses and OER and reflected on teaching practices and the learning outcomes. Those who posted ideas, digital educational material and suggestions, offered peer assistance and support, and carried out the weekly assignments were considered active. During the course, 83 discussion topics were raised, in which 1,530 comments were uploaded and 8,211 visits were recorded which highlights the increased interest of the participants. It should be noted that although we suggested the sparing use of many 'open' threads this suggestion was not followed from the beginning of the course, and a few participants initially preferred to "open" their own discussion thread. However, as the TPD-MOOC progressed, most of the participants followed our initial suggestion. On the first day of the course a synchronous meeting took place to present the aims of the course and answer questions. Respectively, in the last week of the course, on October $29^{\text {th }}, 2020$, a synchronous meeting was held with the aim of reflection and evaluation of the course.

\section{METHOD}

\section{Research Context and Sample}

To investigate the impact of TPD-MOOC on teachers' self-efficacy beliefs and as a result on their professional development we conducted an experimental design research. The first group (experimental group) consisted of 127 in-service elementary school teachers who participated and completed the TPD-MOOC and the second group (control group) consisted of 39 in-service elementary school teachers who had initially expressed interest in attending the $\mathrm{MOOC}$ but did not finally participate in it. All of them had expressed interest after an open call to attend MOOC. They worked in primary schools in Attica, Greece, were volunteers and were selected by a convenient sampling method. Specifically, we asked the participants to complete the questionnaire bio-STEBI-A before and immediately after MOOC, respecting the protocol for the new General Data Protection Regulation. The teachers were informed about the purpose of the study and the dissemination of the results. The data collected would be used solely for research purposes. The data collection process took place in two phases. For both groups there was an initial measurement with the bioSTEBI-A in May 2020. Specifically, in the first phase, before the MOOC, from April $18^{\text {th }}, 2020$, until May $18^{\text {th }}$, 2020, 349 in-service elementary school teachers completed the bio-STEBI-A which is an adaption of "The Science Teaching Efficacy Belief Instrument" (STEBI-A) (Riggs \& Enochs, 1990). It was adapted by the authors to evaluate the self-efficacy beliefs of in-service elementary school teachers in teaching biological concepts, created with Google Forms and administered to the interested via email.

In the second phase, after the MOOC, from November $1^{\text {st }}, 2020$, until November $8^{\text {th }}, 2020$, we administered the bio-STEBI-A to 142 teachers, who completed the TPD-MOOC. In the same period, the questionnaire bioSTEBI-A was administered to the 98 teachers $(349-251=98)$ who had initially expressed interest in attending the TPD-MOOC but did not enroll in it with the request to complete it. The answers of both groups were identified through their emails with the answers they had given to the bio-STEBI-A in the first phase. Hence, according to the above, two groups were formed: the first group consisted of 127 out of 142 teachers who 
Table 1. Participants' demographic characteristics

\begin{tabular}{llcc}
\hline & & Not participated (N=39) & Participated (N=127) \\
\hline Gender & Male & $38.5 \%$ & $17.3 \%$ \\
& Female & $61.5 \%$ & $82.7 \%$ \\
\hline Age & $<=30$ & $12.8 \%$ & $16.5 \%$ \\
& $31-40$ & $25.6 \%$ & $26.8 \%$ \\
& $41-50$ & $28.2 \%$ & $26.0 \%$ \\
\hline Orientation Group of the Last Grade in Lyceum & $>=51$ & $33.4 \%$ & $30.7 \%$ \\
\hline Teaching experience (years) & Sciences & $35.9 \%$ & $22.0 \%$ \\
& Economic \& Computer & $20.5 \%$ & $21.3 \%$ \\
& Humanities & $43.6 \%$ & $56.7 \%$ \\
\hline Postgradute studies & $<=5$ & $17.9 \%$ & $16.5 \%$ \\
& $6-10$ & $7.7 \%$ & $7.9 \%$ \\
Teaching Grade & $11-20$ & $43.6 \%$ & $43.3 \%$ \\
& $>=21$ & $30.8 \%$ & $32.3 \%$ \\
\hline & Yes & $28.2 \%$ & $37.0 \%$ \\
& No & $71.8 \%$ & $63.0 \%$ \\
\hline
\end{tabular}

participated in the MOOC and the second group consisted of 39 out of 98 in-service elementary school teachers who had expressed interest in participating in the MOOC but ultimately did not participate in it. Table 1 shows the demographic characteristics of the two groups.

\section{Research Instrument}

Permission was obtained from the creators (Riggs \& Enochs, 1990) to translate the STEBI-A English version into Greek. The only need was to adapt specific words such as "science (n.)" into "biological contents (n.)" in order for the exact meaning to be clearly conveyed. Within this context the STEBI-A was translated into Greek using a forward and backward translation procedure. Four independent translators, who were fluent in both English and Greek were involved in the process. Initially, two translators converted the scale items from English to Greek. The remaining two translators converted the scale items back to English. All four translators worked independently so as not to be influenced by each other. After that, the two English versions of the questionnaire were compared to the original English STEBI-A. Modifications were made to the Greek versions because of the issues raised from the back-translated items and the fact that the instrument was designed and tested on different working groups in different countries. Cross-cultural adaptation proved to be of great importance. In addition, before the final administration of the instrument, STEBI-A (Greek version) was delivered to 36 teachers, who were excluded from the final sample to detect any comprehension issues. The wording in some items was adjusted to be better conveyed for the Greek context.

The final research instrument included 24 items and consisted of two sections. The first section included items regarding teachers' general characteristics (group of age, gender, type of orientation, teaching experience, postgraduate studies, grade that they usually teach). The second section included 2 subscales. Specifically, it included 13 items of the Personal Biological Teaching Efficacy Belief (PBTE) subscale of bioSTEBI-A and measured teachers' personal self-efficacy beliefs for teaching biological concepts and 11 items of the Biological Teaching Outcome Expectancy (BTOE) subscale of bio-STEBI-A, which measured the outcome expectancy from the teaching of biological concepts. Table $\mathbf{2}$ presents the reliability coefficients (Cronbach's Alpha) in the two subscales (dimensions) of bio-STEBI-A according to the answers of the teachers who filled in the questionnaire before and after the MOOC. Reliability indices (Cronbach's Alpha with values above or very close to 0.8 ) in both subscales indicate that the measurements before and after the MOOC showed satisfactory reliability (Field, 2009). Finally, this instrument has been used for in-service teachers' efficacy beliefs in biological concepts with adequate evidence of validity and the reliability (Angle \& Moseley, 2009; Haney et al., 2007; Mavrikaki \& Athanasiou, 2011). 
Table 2. Reliability of measurements in both dimensions before and after the MOOC ( $N=166)$

\begin{tabular}{llcc}
\hline & & \multicolumn{2}{c}{ Cronbach's Alpha } \\
\hline & Number of items & Before MOOC & After MOOC \\
\hline PBTE & 13 & 0.871 & 0.888 \\
BTOE & 11 & 0.791 & 0.811 \\
\hline
\end{tabular}

Table 3. Results of the independent sample test between two teachers' groups (teachers that participate in MOOC and others), before MOOC

\begin{tabular}{lcccccc}
\hline & \multicolumn{2}{c}{ Not Participated (N=39) } & \multicolumn{2}{c}{ Participated (N=127) } & Mann-Whitney (z) & Effect size (r) \\
\cline { 2 - 7 } & $\mathrm{M}$ & $\mathrm{SD}$ & $\mathrm{M}$ & $\mathrm{SD}$ & & .09 \\
\hline PBTE pre & 3.3 & .69 & 3.4 & .55 & -1.2 & .03 \\
BTOE pre & 3.5 & .53 & 3.6 & .48 & -.4 & .03 \\
\hline
\end{tabular}

\section{Data Analysis}

The data were analyzed using SPSS version 23 (Field, 2009). Initially, we calculated the reliability coefficients of Cronbach's Alpha of two subscales PBTE кaІ BTOE. To compare the measurements of self-efficacy beliefs in two subscales and their corresponding items for the two teachers' groups (teachers that participate in MOOC and others) we used the non-parametric test (independent samples) Mann Whitney. However, to look at how the participation in the MOOC acts on a dependent variable removing the influence of the pretest scores on the posttest scores we carried out a) dependent samples tests and particularly the non-parametric Wilcoxon Signed ranks test and b) non-parametric or rank transformed ANCOVA (Bonate, 2000). Finally, we calculated the effect size for each case (Field, 2009).

\section{RESULTS}

As shown in Table 3, the test of the differentiation of the self-efficacy beliefs of the two groups of teachers according to the two subscales of bio-STEBI-A before participation in the MOOC did not reveal statistically significant differences.

After participating in the MOOC, the test of differentiation of the self-efficacy beliefs of the two groups of teachers according to the two subscales of bio-STEBI-A seems to reveal statistically significant differences (Table 4). Specifically, the teachers that participated in the MOOC seem to have higher scores in both subscales than the teachers who did not participate in the MOOC. Indeed, in most cases we observed medium effect sizes (Field, 2009).

Regarding the dependent samples (pretest and posttest) non-parametric Wilcoxon tests did not reveal statistically significant differences in mean scores for PBTE $(z=-1.65, p>.05, r=.18)$ and BTOE $(z=-.66, p>$ $.05, r=.07)$ in the group of teachers who did not participate in the MOOC and simultaneously the effect sizes were very small (Table 5). However, for the group of teachers who participated in the MOOC the image was different. In both scores PBTE $(z=-8.00, p<.01, r=.50)$ and BTOE $(z=-3.96, p<.01, r=.25)$ the mean posttest scores after the $\mathrm{MOOC}$ were statistically significantly higher than the mean pretest scores before the MOOC, and the correspondent effect sizes varied from medium to high. Finally, using the non-parametric ANCOVA the previous findings are confirmed. Specifically, when the covariate PBTE pretest are controlled for, the participation or not in MOOC presents statistically significant effect on PBTE posttest, $F(1,164)=18.541$, $p=.001, \eta^{2}=.10$. Similarly, when the covariate BTOE pretest are controlled for, the participation or not in MOOC presents statistically significant effect on BTOE posttest, $F(1,164)=10.206, p=.002, \eta^{2}=.06$. 
Table 4. Results of the independent sample test between two teachers' groups (teachers that participate in MOOC and others), after MOOC

\begin{tabular}{|c|c|c|c|c|c|c|}
\hline & \multicolumn{2}{|c|}{$\begin{array}{c}\text { Not } \\
\text { participated } \\
(\mathrm{N}=39)\end{array}$} & \multicolumn{2}{|c|}{$\begin{array}{l}\text { Participated } \\
\qquad(\mathrm{N}=127)\end{array}$} & \multirow[t]{2}{*}{$\begin{array}{l}\text { Mann- } \\
\text { witney } \\
\text { (Z) }\end{array}$} & \multirow[t]{2}{*}{$\begin{array}{l}\text { Effect } \\
\text { Size ( } r)\end{array}$} \\
\hline & $\mathrm{M}$ & SD & M & SD & & \\
\hline 2. I am continually finding more effective ways to teach biological concepts & 4.1 & .83 & 4.6 & .60 & $-3.26^{*}$ & .25 \\
\hline $\begin{array}{l}3^{* *} \text {. Even when I try very hard, I do not teach biological concepts as effective as I do } \\
\text { most subjects }\end{array}$ & 3.1 & 1.14 & 3.4 & 1.12 & -1.51 & .12 \\
\hline 5. I know to teach biological concepts effectively & 3.3 & .89 & 4.0 & .72 & $-4.68 *$ & .36 \\
\hline 6**. I am not very effective in monitoring biological concepts experiments & 3.2 & 1.00 & 3.6 & 1.01 & & .17 \\
\hline 8**. I generally teach biological concepts ineffectively. & 3.4 & .85 & 3.9 & .61 & $-3.89 *$ & .30 \\
\hline $\begin{array}{l}\text { 12. I understand biological concepts well enough to be effective in teaching them in } \\
\text { Primary Education. }\end{array}$ & 3.4 & .82 & 3.9 & .73 & $-3.18^{*}$ & .25 \\
\hline $17^{* *}$. I find it difficult to explain to students how biological concepts experiments work. & 3.3 & 1.00 & 3.8 & 1.01 & $-2.65^{*}$ & .21 \\
\hline 18. I am typically able to answer students' biolog & 3.7 & .90 & 4.1 & .65 & $-3.02 *$ & .23 \\
\hline $19 * *$ I wonder if I have the necessary skills to teach biological concepts. & 3.3 & 1.00 & 3.6 & 1.14 & -1.42 & .11 \\
\hline $\begin{array}{l}21^{* *} \text {. Given a choice, I would not invite the principal to evaluate my biological concepts } \\
\text { teaching }\end{array}$ & 3.4 & 1.18 & 3.7 & 1.12 & -1.69 & .13 \\
\hline $\begin{array}{l}22^{* *} \text {. When a student has difficulty understanding biological concepts, I am usually at a } \\
\text { loss how to help the student understand it better. }\end{array}$ & 3.6 & 1.02 & 4.0 & .97 & $-2.33^{*}$ & .18 \\
\hline come student questions & 4.1 & .82 & 4.5 & .65 & $-2.77^{*}$ & .22 \\
\hline $24^{* *} .1$ do & 3.5 & 1.07 & 4.1 & .95 & $2.81^{*}$ & .22 \\
\hline Mean PBTE post & 3.5 & .60 & 3.9 & .60 & $-4.10 *$ & .32 \\
\hline $\begin{array}{l}\text { er than usual in biological concepts, it is because the } \\
\text { rt. }\end{array}$ & 3.6 & .85 & 3.8 & .75 & -1.45 & .11 \\
\hline $\begin{array}{l}\text { 4. When the biological concepts grades of students improve, it is most often due to their } \\
\text { teacher having found a more effective teaching approach. }\end{array}$ & 3.9 & .74 & 4.2 & .61 & $-2.11^{*}$ & .16 \\
\hline $\begin{array}{l}\text { 7. If students are underachieving in biological concepts, it is most likely due to } \\
\text { ineffective biological concepts teaching. }\end{array}$ & 3.7 & .77 & 3.5 & .84 & -1.17 & .09 \\
\hline $\begin{array}{l}\text { 9. The inadequacy of student's biological concepts background can be overcome by } \\
\text { effective teaching. }\end{array}$ & 4.1 & .66 & 4.4 & .62 & $-3.21 *$ & .25 \\
\hline $\begin{array}{l}10^{* *} \text {. Teachers are not to blame for the low performance of some students in biological } \\
\text { concepts. }\end{array}$ & 2.7 & .95 & 3.1 & .90 & $-2.66^{*}$ & .21 \\
\hline $\begin{array}{l}\text { 11. When a low achieving child progresses in biological concepts, it is usually due to } \\
\text { extra attention given by the teacher. }\end{array}$ & 3.6 & .75 & 3.8 & .72 & -1.05 & .08 \\
\hline $\begin{array}{l}\text { 14. The teacher is generally responsible for the achievement of students in biological } \\
\text { concepts. }\end{array}$ & 3.4 & .78 & 3.3 & .80 & -0.32 & .03 \\
\hline $\begin{array}{l}\text { 15. Students' achievement in biological concepts is directly related to their teacher's } \\
\text { effectiveness in biological concepts teaching. }\end{array}$ & 3.5 & .76 & 3.7 & .76 & -1.70 & .13 \\
\hline $\begin{array}{l}\text { 16. If parents comment that their child is showing more interest in biological concepts at } \\
\text { school, it is probably due to the performance of the child's teacher. }\end{array}$ & 3.5 & .85 & 4.0 & .64 & $-3.55^{*}$ & .28 \\
\hline $\begin{array}{l}20^{* *} \text {. Effectiveness in teaching biological concepts does not greatly affect the } \\
\text { performance of low-motivation students. }\end{array}$ & 3.4 & .88 & 3.7 & .89 & -1.76 & .14 \\
\hline $\begin{array}{l}25^{* *} \text {. No matter how well the teacher teaches the biological concepts, he/she cannot } \\
\text { help some children to understand the biological concepts in depth. }\end{array}$ & 3.1 & 1.17 & 3.6 & .98 & $-2.72^{*}$ & .21 \\
\hline Mean BTOE post & 3.5 & .50 & 3.7 & .50 & $-2.85 *$ & .22 \\
\hline
\end{tabular}

* Differences are significant at the .05 level (2-tailed).

** For these negative wording items, we have reversed the responses.

The statements of the instrument have been adapted to measure biological concepts at the initial measurement (Tzovla \& Kedraka, 2020).

Table 5. Results of the dependent samples (pre \& post) tests in each condition (teachers that participate in MOOC and others)

\begin{tabular}{|c|c|c|c|c|c|c|}
\hline & \multicolumn{2}{|c|}{ Pretest } & \multicolumn{2}{|c|}{ Posttest } & \multirow{2}{*}{$\begin{array}{l}\text { Wilcoxon } \\
\text { Signed (z) }\end{array}$} & \multirow{2}{*}{ Effect Size ( $r$ ) } \\
\hline & $M$ & SD & $\mathrm{M}$ & SD & & \\
\hline \multicolumn{7}{|c|}{ Not participated $(\mathrm{N}=39)$} \\
\hline PBTE & 3.3 & .69 & 3.5 & .62 & -1.65 & .18 \\
\hline BTOE & 3.5 & .53 & 3.5 & .53 & -.66 & .07 \\
\hline \multicolumn{7}{|c|}{ Participated $(\mathrm{N}=127)$} \\
\hline PBTE & 3.4 & .55 & 3.9 & .56 & $-8.00 *$ & .50 \\
\hline BTOE & 3.6 & .48 & 3.7 & .50 & $-3.96 *$ & .25 \\
\hline
\end{tabular}

* Differences are significant at the .01 level (2-tailed). 


\section{DISCUSSION}

The main goal of this study was on the one hand to design a TPD-MOOC and at the same time investigate its effectiveness in improving participants' self-efficacy beliefs through an experimental research. The selfefficacy beliefs of the two groups of teachers before their participation in the TPD-MOOC did not reveal any differences. However, the findings indicated that teachers who completed the TPD-MOOC demonstrated improved self-efficacy beliefs as compared to those who did not participate in the course. Additionally, the comparison of mean scores pretest and posttest revealed a statistically significant increase of posttest scores only in the group of teachers who participated in the TPD-MOOC. Therefore, the teachers that participated in the MOOC seem to have higher scores in both subscales than the teachers who did not participate in the MOOC, after partialling out the effect that the covariate (pretest scores) has on the outcome (posttest).

The engagement in activities, which utilized digital educational content and OER, seems to have enhanced the self-efficacy beliefs in teaching biological concepts of the participants. Specifically, regarding the PBTE the teachers that participated in the TPD-MOOC seem to have especially improved personal self-efficacy beliefs in a) teaching biological concepts effectively, b) finding more effective ways to teach biological concepts, c) understanding biological concepts well enough to be effective in teaching them in Primary Education and d) they are typically able to answer students' biological concepts questions. Similarly, with regard to BTOE teachers presented particular improved outcome expectancy self-efficacy beliefs in the following statements: a) if parents comment that their child shows more interest in biological concepts at school, it is probably due to the performance of the child's teacher, b) the inadequacy of student's biological concepts background can be overcome by effective teaching, c) teachers can help some children to understand the biological concepts in depth and d) teachers are to blame for the low performance of some students in biological concepts. It is worth noting that the results of our study indicated a small but significant improvement of BTOE. A small number of studies (Aji \& Khan, 2019; Gosselin et al., 2010), have shown improved results in this subscale, including the present, which allows the conclusion that the design and implementation of this MOOC satisfied several conditions that contributed to the improvement of the outcome expectancy self-efficacy beliefs.

According to our findings Greek in-service elementary school teachers improved their self-efficacy beliefs thus going in line with Aji and Khan (2019), Gosselin et al. (2010), Mertasari and Candiasa (2020), and Yoo (2016) who reported the same findings. However, our results do not comply with the findings of Wang and Zhu (2019) who reported no change in undergraduate chemistry students' self-efficacy.

Moreover, the forum seems to have been a very supportive tool since it promoted peer support and peer teaching (Koukis \& Jimoyiannis, 2017, 2019). It should be noted that the high rate of posts per participant boosted the elements of our course. Specifically, they are in accordance with the findings of Gosselin et al. (2010) that the collaboration and interaction in a learning community improve skills and teaching practices, Reddy and Pabolu (2019) that online educational environments promote active learning, Moreno-Marcos et al. (2020) that the self-regulated learning directed teachers to determine learning trajectories and reduce dropout, and Reddy and Pabolu (2019) who highlight the important role of educators in online learning environments. It is true that the average comments per participant were three posts per week and all participants posted at least a comment. It is worth mentioning that most comments ( 472 in number) were recorded in the $3^{\text {rd }}$ module during which the participants had to design their activities with OER for teaching biological concepts in primary school. It was impressive that many digital educational recourses were inquired and posted by the participants and a great number of activities for the teaching of biological concepts in Elementary Education were created and implemented. Additionally, important issues regarding the importance of teaching biological concepts in elementary schools, the utilization of the digital recourses and OER in the classroom and their contribution to teachers' self-efficacy beliefs were raised in the forums.

Finally, the high rate of course completion provides supportive evidence that the course met the teachers' needs and contributed to their self-efficacy beliefs. Specifically, the community-centered approach enhanced the collaborative participation, interaction, sharing of experiences, knowledge and learning, flexibility, and autonomous and self-directed learning (Koukis \& Jimoyiannis, 2019), which contributed to improve teachers' 
self-efficacy beliefs. In addition, the ongoing encouragement and support and the positive feedback from the educators (Reddy \& Pabolu, 2019) and the fact that the TPD-MOOC is directed to a homogeneous group of participants, who learned from more experienced and/or less experienced colleagues, came into contact with work of other colleagues and applied their achievements directly to their classroom, encouraged them to act as "learners" and "designers" and, ultimately, improved their self-efficacy beliefs.

\section{CONCLUSION, LIMITATIONS, AND FUTURE RESEARCH}

An overarching conclusion of our study is that a design framework of a TPD-MOOC, which relates to the curriculum, puts emphasis on active online learning communities, enhances self-regulated and flexible learning, promotes the role of participants as learners and designers of teaching proposals and the role of educators as encouragers and critical friends and especially considers the educational needs of participants can have positive impact on teachers' self-efficacy beliefs. A few studies (Oh et al., 2019) investigate the educational needs of participants before designing a MOOC. Our TPD-MOOC aimed at the personalized learning experience to suit participants learning needs and this is an element of our MOOC that seems to play an important role in the effectiveness of our course. It will thus act as a springboard for future research as the effectiveness of TPD-MOOCs is an under-researched field (Zhu et al., 2020).

Of special interest would be to re-evaluate the self-efficacy beliefs of the participants of our TPD-MOOCs after a long period (six months or a year) to determine if they maintain the level of self-efficacy they had after the end of our course and continue to apply the teaching practices and digital educational content that they had implemented during our TPD-MOOC. Moreover, findings of our study underscore the importance of educational needs of participants in the design of TPD-MOOCs. Hence future studies could investigate the effectiveness of a course which includes teachers in the design and implementation of it and makes them cocreators of the course (Cober et al., 2015). Our study shed light on the impact that a TPD-MOOC has on the self-efficacy beliefs of teachers. Thus, it could be the basis for the design framework of courses for other specialties of teachers to explore if it had had a positive impact on their self-efficacy beliefs, too. Furthermore, it would be interesting to analyze the effectiveness of a TPD-MOOC according to the profile and background of participants (Wang \& Zhu, 2019) and the relationship between effectiveness and time and quality of teachers' participation in the learning community.

Despite the fact that the study was limited by the specific sample and context, TPD-MOOCs provides a useful framework for designers and educators. Truly, a TPD-MOOC model, which incorporates community-centered approach and self-directed learning and collaboration within learning communities, connects theory with classroom reality, offers flexibility and appropriate educational material, enhances sharing ideas, teaching practices and creation of activities relevant to the curriculum, as Koukis and Jimoyiannis $(2017,2019)$ argue, attributes to the participants the role of guiders and to the instructors the role of encouragers, investigates the educational needs of participants and ascertains to reduce dropout by creating conditions that facilitate course attendance could support teachers' professional development.

Finally, considering the methods of our study, we recognize that this study had some limitations. One limitation is that the expression of personal beliefs is a theme that may be biased (Lavidas \& Gialamas, 2019). Another limitation is the fact that there are not enough studies which put emphasis on the effect of TPDMOOCs on teachers' self-efficacy beliefs. Moreover, our study claims that the TPD-MOOC has a positive impact on teachers' self-efficacy beliefs, but it is only an aspect of teachers' professional development. Our study provided the evidence that TPD-MOOCs can be an effective solution to the unavoidable teachers' educational needs and highlights the contribution of them in the improvement of teachers' self-efficacy beliefs. Given the increased interest about them, the ICT evolution, and the COVID-19 pandemic, they are rated as an appropriate choice for teachers' professional development.

Author contributions: All authors were involved in concept, design, collection of data, interpretation, writing, and critically revising the article. All authors approve final version of the article.

Funding: The authors received no financial support for the research and/or authorship of this article.

Declaration of interest: Authors declare no competing interest.

Data availability: Data generated or analysed during this study are available from the authors on request. 


\section{REFERENCES}

Aji, C., \& Khan, M. (2019). A Flight Simulator-Based Active Learning Environment. Open Journal of Social Sciences, 7, 192-203. https://doi.org/10.4236/jss.2019.73016

Aldowah, H., Al-Samarraie, H., Alzahrani, A. I., \& Alalwan, N. (2019). Factors affecting student dropout in MOOCs: a cause-and-effect decision-making model. Journal of Computing in Higher Education, 1-26. https://doi.org/10.1007/s12528-019-09241-y

Angle, J., \& Moseley, C. (2009). Science teacher efficacy and outcome expectancy as predictors of students' end-of-instruction (EOI) biology I test scores. School Science and Mathematics, 109(8), 473-483. https://doi.org/10.1111/j.1949-8594.2009.tb18294.x

Bandura, A. (1997). Self-efficacy: The exercise of control. W H Freeman/Times Books/ Henry Holt \& Co.

Bolam, R. (2000). Emerging policy trends: Some implications for continuing professional development. Journal of In-Service Education, 26(2), 267-280. https://doi.org/10.1080/13674580000200113

Bonate P. L. (2000). Analysis of Pretest-Posttest Designs. Chapman and Hall/CRC Press. https://doi.org/10.1201/9781420035926

Bruff, D. O., Fisher, D. H., McEwen, K. E., \& Smith, B. E. (2013). Wrapping a MOOC: Student perceptions of an experiment in blended learning. Journal of Online Learning and Teaching, 9(2), 187-199.

Cober, R., Tan, E., Slotta, J., So, H. J., \& Könings, K. D. (2015). Teachers as participatory designers: Two case studies with technology-enhanced learning environments. Instructional Science, 43(2), 203-228. https://doi.org/10.1007/s11251-014-9339-0

Conole, G. (2014). A new classification schema for MOOCs. The International Journal for Innovation and Quality in Learning, 2(3), 65-77.

Depover, C., Karsenti, T., \& Komis, V. (2017). Pour comprendre les MOOCs - Nature, enjeux et perspectives. Presses de l'Universite du Quebec.

Dimitriadou, S., Lavidas, K., Karalis, T., Ravanis, K. (2021). Study engagement in university students: A confirmatory factor analysis of the Utrecht work engagement scale with Greek students. Journal of Weil-Being Assessment. https://doi.org/10.1007/s41543-021-00035-7

Evans, L. (2014). Leadership for professional development and learning: Enhancing our understanding of how teachers develop. Cambridge Journal of Education, 44, 179-198. https://doi.org/10.1080/0305764X.2013.860083

Field, A. (2009). Discovering statistics using IBM SPSS statistics (3rd ed.). SAGE.

Firmin, R., Schiorring, E., Whitmer, J., Willett, T., Collins, E. D., \& Sujitparapitaya, S. (2014). Case study: Using MOOCs for conventional college coursework. Distance Education, 35(2), 178-201. https://doi.org/10.1080/01587919.2014.917707

Fishman, B., Konstantopoulos, S., Kubitskey, B. W., Vath, R., Park, G., Johnson, H., \& Edelson, D. C. (2013). Comparing the impact of online and face-to-face professional development in the context of curriculum implementation. Journal of Teacher Education, 64(5), 426-438. https://doi.org/10.1177/0022487113494413

Gamage, D., Perera, I., \& Fernando, S. (2016). Evaluating effectiveness of MOOCs using empirical tools: Learners' perspective. In The 10th International Technology, Education and Development Conference (pp. 8276-8284). Valencia, Spain 2016. https://doi.org/10.21125/inted.2016.0937 
Goh, W. W., Wong, S. Y., \& Ayub, E. (2018). The effectiveness of MOOC among learners based on kirkpatrick's model. In Redesigning learning for greater social impact (pp. 313-323). Springer, Singapore. https://doi.org/10.1007/978-981-10-4223-2_29

Goodyear, P., Banks, S., Hodgson, V., \& McConnell, D. (2004). Advances in research on networked learning. Kluwer Academic.

Gordillo, A., López-Pernas, S., \& Barra, E. (2019). Efectividad de los MOOC para docentes en el uso seguro de las TIC [Effectiveness of MOOCs for teachers in safe ICT use training]. Comunicar, 61, 103-112. https://doi.org/10.3916/C61-2019-09

Gosselin, D. C., Thomas, J., Redmond, A., Larson-Miller, C., Yendra, S., Bonnstetter, R. J., \& Slater, T. F. (2010). Laboratory earth: A model of online K-12 teacher coursework. Journal of Geoscience Education, 58(4), 203-213. https://doi.org/10.5408/1.3534859

Greene, J. A., Oswald, C. A., \& Pomerantz, J. (2015). Predictors of retention and achievement in a massive open online course. American Educational Research Journal, 52(5), 925-955. https://doi.org/10.3102/0002831215584621

Haney, J. J., Wang, J., Keil, C., \& Zoffel, J. (2007). Enhancing teachers' beliefs and practices through problembased learning focused on pertinent issues of environmental health science. The Journal of Environmental Education, 38(4), 25-33. https://doi.org/10.3200/JOEE.38.4.25-33

Kaplan, A. M., \& Haenlein, M. (2016). Higher education and the digital revolution: About MOOCs, SPOCs, social media, and the cookie monster. Business Horizons, 59(4), 441-450. https://doi.org/10.1016/j.bushor.2016.03.008

Karalis, T., \& Koutsonikos, G. (2003). Issues and challenges in organizing web-based 518 courses for adults. Themes in Education, 4(2), 177-188.

Karlsson, N., Godhe, A., Bradley, L., \& Lindström, B. (2014). Professional development of teachers in a MOOC. Proceedings of the 22nd International Conference on Computers in Education, 868-877. Asia-Pacific Society for Computers in Education, Japan. http://docplayer.net/139059

Kedraka, K. (2008). Supporting the professional development of teachers in a school unit: 523 principles, prerequisites, and suggestions. Ta Ekpaideutika, 87-88, 111-124. [in Greek]

Keefer, J. M. (2009). The critical incident questionnaire (CIQ): From research to practice and back again. In Proceedings of the 50th Annual Adult Education Research Conference (pp. 177-180). https://newprairiepress.org/aerc/2009/papers/31/

Khalil, H., \& Ebner, M. (2014). MOOCs completion rates and possible methods to improve retention - A literature review. In Proceedings of World Conference on Educational Multimedia, Hypermedia and Telecommunications 2014 (pp. 1236-1244). AACE.

Koukis, N., \& Jimoyiannis, A. (2017). Designing MOOCs for teacher professional development: Analysis of participants' engagement. In A. Mesquita \& P. Peres (Eds.), Proceedings of the 16th European Conference on e-Learning, ECEL 2017 (pp. 271-280). ACPI.

Koukis, N., \& Jimoyiannis, A. (2019). MOOCS for teacher professional development: exploring teachers' perceptions and achievements. Interactive Technology and Smart Education, 16(1), 74-91. https://doi.org/10.1108/ITSE-10-2018-0081

Lavidas, K., \& Gialamas, V. (2019). Adaption and psychometric properties of the short forms Marlowe-Crowne social desirability scale with a sample of Greek university students. European Journal of Education Studies, 6(8), 230-239. https://doi.org/10.5281/zenodo.3552531 
Mavrikaki, E., \& Athanasiou, K. (2011). Development and application of an instrument to measure Greek primary education teachers' biology teaching self-efficacy beliefs. EURASIA Journal of Mathematics, Science and Technology Education, 7(3), 203-213. https://doi.org/10.12973/ejmste/75197

Menon, S., \& Banerjee, G. (2019). Evaluating effectiveness of a teacher training MOOC: Industry perspective. In 2019 IEEE Tenth International Conference on Technology for Education (T4E) (pp. 102-105). IEEE. https://doi.org/10.1109/T4E.2019.00-42

Mertasari, N. M. S., \& Candiasa, I. M. (2020). Improving self-efficacy in the teaching of prospective mathematics teachers by involving them in the online teacher community. Journal of Physics: Conference Series, 1516(1), 012038. https://doi.org/10.1088/1742-6596/1516/1/012038

Moreno-Marcos, P. M., Muñoz-Merino, P. J., Maldonado-Mahauad, J., Pérez-Sanagustín, M., Alario-Hoyos, C., \& Kloos, C. D. (2020). Temporal analysis for dropout prediction using self-regulated learning strategies in self-paced MOOCs. Computers \& Education, 145, 103728. https://doi.org/10.1016/j.compedu.2019.103728

Oh, E. G., Chang, Y., \& Park, S. W. (2019). Design review of MOOCs: Application of e-learning design principles. Journal of Computing in Higher Education, 1-21. https://doi.org/10.1007/s12528-019-09243-w

Onah, D. F., Sinclair, J., \& Boyatt, R. (2014). Dropout rates of massive open online courses: behavioural patterns. EDULEARN14 Proceedings, 1, 5825-5834.

Ostashewski, N. (2018). MOOCs for Teachers: Understanding Learning in Networked Teacher Professional Development. In E. Langran \& J. Borup (Eds.), Proceedings of Society for Information Technology \& Teacher Education International Conference (pp. 230-233). Association for the Advancement of Computing in Education (AACE).

Pavlis-Korres, M., Karalis, T., Leftheriotou, P., \& Barriocanal, E.G. (2009). Integrating adults' 568 characteristics and the requirements for their effective learning in an e-learning 569 environment, 2 nd World Summit on the Knowledge Society, Chania, Greece, 16-18 570 September 2009. In M. D. Lytras, P.O. de Pablos, E. Damiani, D. Avison, A. Neave, \& 571 D.G. Horner (Eds.), Best practices for the knowledge society: Knowledge, 572 learning, development and technology for all (pp. 570-584). Springer.

Rahimi, E., Henze, I., Hermans, F., \& Barendsen, E. (2018). Investigating the pedagogical content knowledge of teachers attending a MOOC on Scratch programming. In S. Pozdniakov \& V. Dagienè (Eds.), Informatics in Schools. Fundamentals of Computer Science and Software Engineering. ISSEP 2018. Lecture Notes in Computer Science (vol. 11169, pp. 180-193). Springer, Cham. https://doi.org/10.1007/978-3-030-02750-6-14

Reddy, K. R., \& Pabolu, V. K. R. (2019). Case study on effectiveness of MOOCs lessons for the rural technical education. In Proceedings of International Conference on Digital Pedagogies (ICDP). https://doi.org/10.2139/ssrn.3377627

Riggs, I. M., \& Enochs, L. G. (1990). Toward the development of an elementary teacher's science teaching efficacy belief instrument. Science Education, 74(6), 625-637. https://doi.org/10.1002/sce.3730740605

Ross, J., Sinclair, C., Knox, J., Bayne, S., \& Macleod, H. (2014). Teacher experiences and academic identity: The missing components of MOOC pedagogy. Journal of Online Learning and Teaching, 10(1), 57-69.

Rozimela, Y. (2020). Developing teachers' professionalism through school initiative-based lesson study. European Journal of Educational Research, 9(4), 1513-1526. https://doi.org/10.12973/eu-jer.9.4.1513

Schroeder, A. (2019). Examining the moderating impacts of classroom experience on the relationship between elementary teachers' beliefs and science instruction (Doctoral dissertation), Texas Tech University. 
Siemens, G. (2013). Massive open online courses: Innovation in education? Open Educational Resources: Innovation, Research and Practice, 5, 5-15.

Swart, F., Knezic, D., Onstenk, J., \& de Graaff, R. (2019). Evaluating and improving teacher educators' languageoriented performance in content-based teaching. International Journal of Educational Methodology, 5(1), 71-86. https://doi.org/10.12973/ijem.5.1.71

Sykes, G. (1996). Reform of and as professional development. Phi Delta Kappan, 77(7), 464-467.

Tzovla, E., \& Kedraka, K. (2020). Personal biology teaching efficacy beliefs and biology teaching outcome expectancy of in-service elementary teachers. European Journal of Education Studies, 7(10), 143-159. https://doi.org/10.46827/ejes.v7i10.3286

Tzovla, E., Kedraka, K., \& Kaltsidis, C. (2021). Investigating in-service elementary school teachers' satisfaction with participating in $\mathrm{MOOC}$ for teaching biological concepts. Eurasia Journal of Mathematics, Science and Technology Education, 17(3), em1946. https://doi.org/10.29333/ejmste/9729

Wang, K., \& Zhu, C. (2019). MOOC-based flipped learning in higher education: students' participation, experience and learning performance. International Journal of Educational Technology in Higher Education, 16(1), 1-18. https://doi.org/10.1186/s41239-019-0163-0

Yoo, J. H. (2016). The effect of professional development on teacher efficacy and teachers' self-analysis of their efficacy change. Journal of Teacher Education for Sustainability, 18(1), 84-94. https://doi.org/10.1515/jtes-2016-0007

Zhu, M., Sari, A. R., \& Lee, M. M. (2020). A comprehensive systematic review of MOOC research: Research techniques, topics, and trends from 2009 to 2019. Educational Technology Research and Development, 68(4), 1685-1710. https://doi.org/10.1007/s11423-020-09798-x

Correspondence: Eirini Tzovla, Department of Molecular Biology \& Genetics, Democritus University of Thrace, Evros, Greece. E-mail: etzovla@mbg.duth.gr 